\title{
Carbon capture and sequestration in power generation: review of impacts and opportunities for water sustainability
}

\author{
Hisham Eldardiry ${ }^{1,2^{*}}$ and Emad Habib ${ }^{1}$
}

\begin{abstract}
This article reviews the use of carbon capture and sequestration (CCS) as a viable mitigation strategy for reducing greenhouse gas (GHG) emissions in fossil-fuel power plants and discusses the impacts on the sustainability of freshwater resources. While CCS technology can significantly mitigate anthropogenic GHG emissions, CCS installations are expected to impose new water stresses due to additional water requirements for chemical and physical processes to capture and separate $\mathrm{CO}_{2}$. In addition to these processes, the parasitic loads imposed by carbon capture on power plants will reduce their efficiency and thus require more water for cooling the plant. Groundwater contamination due to $\mathrm{CO}_{2}$ leakage during geologic sequestration is an additional concern when adapting CCS into power plants. Imposing such constraints on the quantity and quality of freshwater resources will influence decisions on the types of energy facilities and threaten the sustainability of water systems. A review of recent studies highlights three main challenges that would impact water sustainability due to CCS installation: (1) water requirements needed for different stages of CCS, (2) changes in groundwater quality due to carbon leakage into geologic formations, and (3) opportunities for using desalinated brine from saline sequestration aquifers to provide new freshwater sources and offset the CCS-induced water stresses. This article also reviews availability and gaps in datasets and simulation tools that are necessary for an improved CCS analysis. Illustrative analyses from two US states, Louisiana and Arizona, are presented to examine the possible consequences of introducing CCS technologies into existing power plants. A basin-scale, water stress framework is applied to estimate the added stresses on freshwater resources due to CCS installations. The scenario-based illustrative examples indicate the need for a full analysis of the inter-relationship between implementing different CCS technologies in the electric generation sector and the water system. Such analyses can be examined in future studies via an integrated energywater nexus approach. Furthermore, the current article highlights the need for integrating the environmental, economic, and societal aspects of CCS deployment into future assessment of the viability of CCS operations and how to make water systems less vulnerable to CCS impacts.
\end{abstract}

Keywords: CCS, Sustainability, Carbon capture, Water stress, Sequestration, Energy-Water nexus, Carbon emission

\section{Background}

Climate change due to anthropogenic emissions of greenhouse gases (GHGs) is one of the most significant longterm environmental challenges facing the United States (US) and the world [1,2]. Since 1990, the largest source of GHG emissions in the US has been due to carbon dioxide emission $\left(\mathrm{CO}_{2}\right)$, with the electricity sector accounting for

\footnotetext{
* Correspondence: hae5018@louisiana.edu

'Department of Civil Engineering \& Institute for Coastal and Water Research, University of Louisiana at Lafayette, Lafayette, LA 70504, USA

${ }^{2}$ Currently at University of Washington, Seattle, WA 98195, USA
}

about one third of the US total emissions. GHG emissions from the electricity sector have increased with the growth of electricity demands and with fossil fuels remaining as the dominant source for electricity generation [3]. Figure 1 shows the distribution of power plants in the US that use fossil fuels as the primary source of energy (e.g., natural gas, coal, and petroleum).

A wide range of mitigation strategies have been developed to reduce $\mathrm{CO}_{2}$ emissions [4]. Technological alternatives for reducing $\mathrm{CO}_{2}$ emissions from power plants to the atmosphere include the following: (a) switching to 


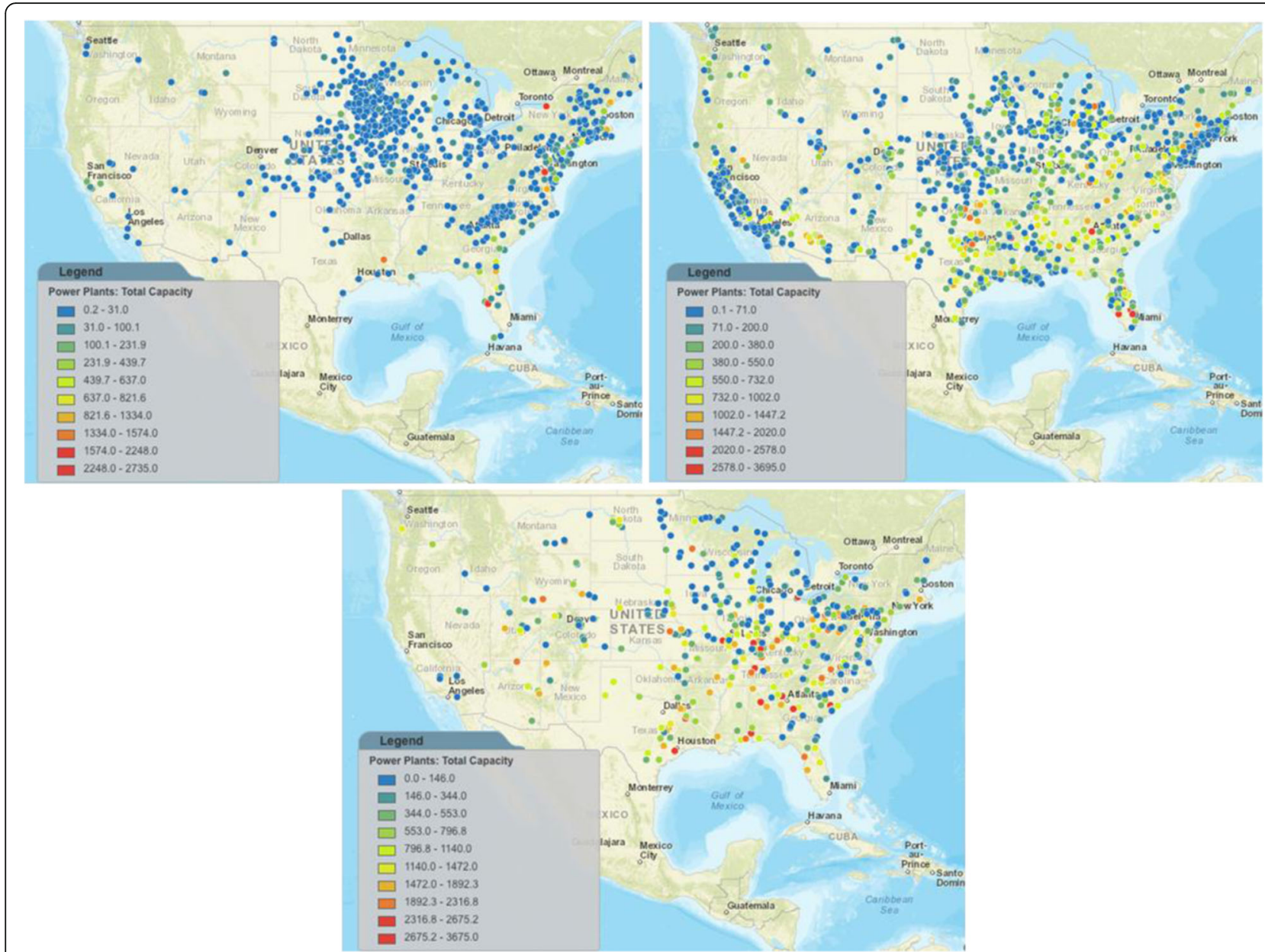

Fig. 1 Locations of fossil fuel-fired power plants in the US using petroleum (top left panel), natural gas (top right panel), and coal (lower panel). The plants are color-coded according to their total capacity in megawatt hours (MWh). Data on individual power plants were acquired from US Energy Information Administration (EIA). Graphs are generated using the Energy-Water nexus site (http://nexus.hydroviz.org)

less carbon-intensive fuels, for example natural gas instead of coal; (b) increasing the use of renewable energy sources or nuclear energy, each of which emits little to no net $\mathrm{CO}_{2}$; and (c) capturing and sequestrating $\mathrm{CO}_{2}$ [5]. The subject of this article will focus on the third option, $\mathrm{CO}_{2}$ capture and sequestration (CCS), as an efficient strategy to limit climate destabilization due to high levels of energy-related $\mathrm{CO}_{2}$ emissions. $\mathrm{CCS}$ is a highly promising approach to reducing GHG emissions by capturing $\mathrm{CO}_{2}$ at the site of the power plant, transporting it to an injection site, and sequestrating for long-term storage in suitable formations [6, 7]. Installation of a CCS unit at thermoelectric plants can efficiently capture about $85-95 \%$ of the $\mathrm{CO}_{2}$ processed in a capture plant $[8,9]$.

Water is an integral element of CCS processes. Since water is used for cooling and emission scrubbing, deployment of CCS will potentially increase water withdrawals to meet the added needs for chemical and physical processes of capturing and separating large volumes of $\mathrm{CO}_{2}[10,11]$.
Thus, the CCS technologies are expected to significantly introduce additional stresses on the sustainability of water systems. In addition to water needs, a power plant with a CCS system would also need roughly 10-40\% more energy than a plant of equivalent output without CCS [12]. Therefore, there is a need to enhance the scientific understanding and predictive capabilities on the interactions between the sustainability of the water system and CCS operations, including the threefold considerations of economic feasibility, social responsibility, and environmental integrity. The current article reviews existing literature and discusses outstanding research questions related to the following issues:

(1)Quantitative analysis and modeling approaches for predicting water requirements for different stages of CCS implementation

(2)Impact on groundwater quality due to potential carbon leakage in geologic formations and related consequences to freshwater availability 
(3) Opportunities for using desalinated brine extracted from saline sequestration aquifers to provide additional freshwater resources

(4)Environmental, economic, and societal impacts due to the installation of a CCS unit at a power plant

The remainder of this article is organized as follows. A brief overview of the CCS processes is introduced. Then, the implications for the water system due to the installation of CCS technologies at power plant facilities are presented along with a discussion of available datasets and simulation tools that can be used to enhance the understanding of CCS water requirements and impacts on groundwater. The rest of the article presents some illustrative examples on the potential for CCS deployments and the expected impacts on the water system in selected regions in the southwest of the US. Besides the CCS impacts on the water system, the article reviews other key factors such as environmental, economic, and societal impacts facing the deployment of CCS. Concluding remarks are presented in the last section.

\section{Carbon capture and sequestration (CCS)}

CCS technology is a viable mitigation option for reducing GHG emissions in fossil-fuel power plants. There are three main components of the CCS process: capturing $\mathrm{CO}_{2}$ arising from the combustion of fossil fuels, transporting $\mathrm{CO}_{2}$ to the storage site, and storing $\mathrm{CO}_{2}$ for a long period of time, rather than being emitted to the atmosphere.

The three common technologies for $\mathrm{CO}_{2}$ capture in CCS systems are the following: post-combustion capture, pre-combustion capture, and oxy-fuel capture [13-15]. In post-combustion capture, $\mathrm{CO}_{2}$ is separated from the flue gases before they are discharged to the atmosphere. The most commercially common method, amine scrubbing, is based on using amine gas treating to remove $\mathrm{CO}_{2}$ by aqueous solutions of amines [16]. The $\mathrm{CO}_{2}$ removed from the amine solvent is then dried and compressed to reduce its volume before being transported to a safe storage site (Fig. 2). The pre-combustion capture of $\mathrm{CO}_{2}$ is based on the ability to gasify all types of fossil fuels with oxygen or air and/or steam to produce a synthesis gas (syngas) or fuel gas composed of carbon monoxide and hydrogen. Additional water (steam) is then added and the mixture is passed through a series of catalyst beds for the water-gas shift reaction to approach equilibrium, after which $\mathrm{CO}_{2}$ can be separated to leave a hydrogen-rich fuel gas. This hydrogen can be sent to a turbine to produce electricity or used in hydrogen fuel cells of transportation vehicles. Although the energy requirements in pre-combustion capture systems may be of the order of half that required in post-combustion capture, the pre-combustion process requires more water for the water-gas shift reaction. In the oxy-fuel capture, pure oxygen is used for combustion instead of air and gives a flue gas mixture of mainly $\mathrm{CO}_{2}$ and condensable water vapor, which can be separated and cleaned relatively easily during the compression process.

After the $\mathrm{CO}_{2}$ is captured, it gets compressed to a supercritical fluid with properties between those of a gas and a liquid. It is then transported to a location suitable for long-term storage. Multiple factors are typically considered when selecting $\mathrm{CO}_{2}$ storage sites: volume, purity,

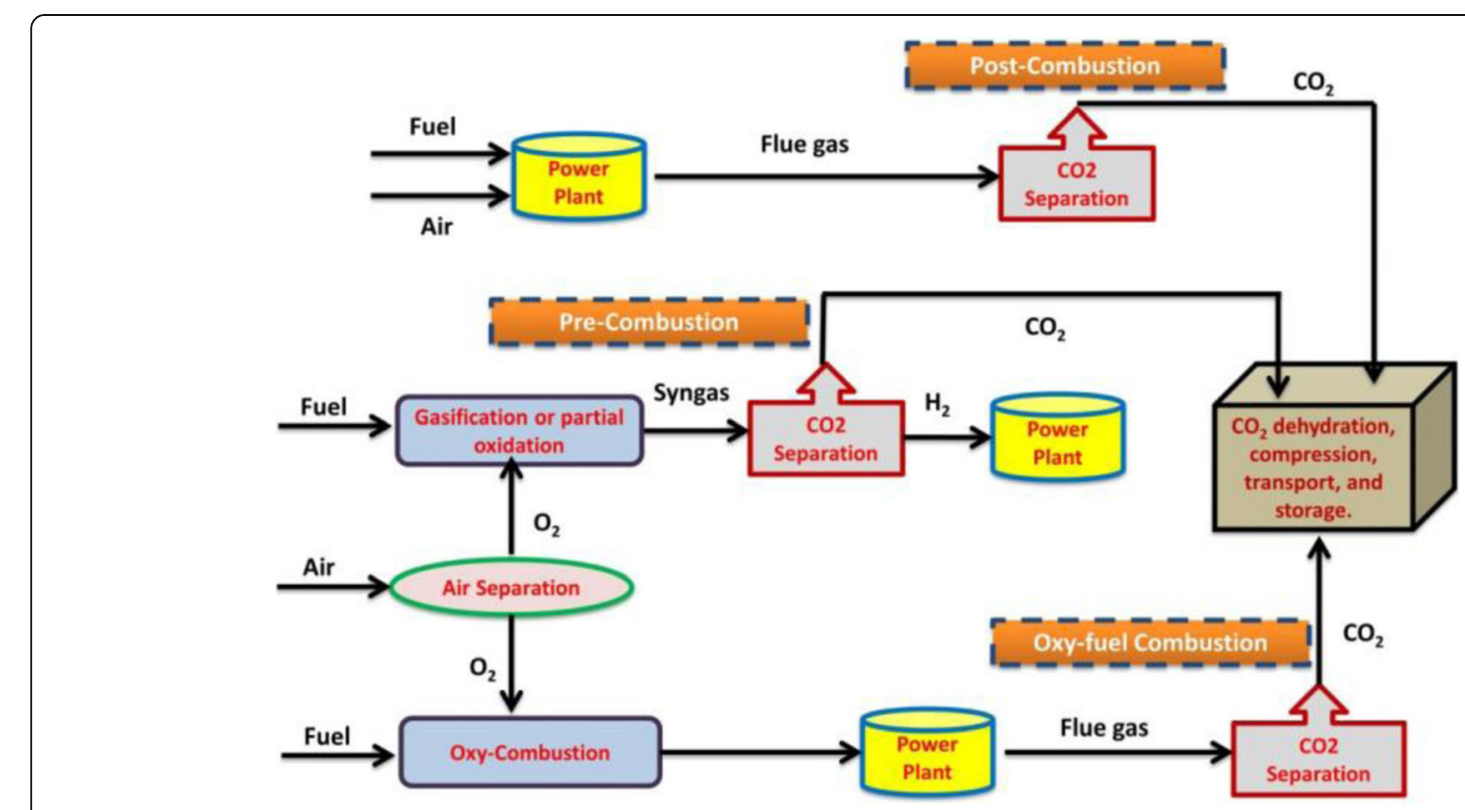

Fig. 2 Principles of $\mathrm{CO}_{2}$ capture technologies (adapted from [16]) 
and rate of the $\mathrm{CO}_{2}$ stream; proximity of the source and storage sites; infrastructure for the capture and delivery of $\mathrm{CO}_{2}$; existence of groundwater resources; and safety of the storage site $[17,18]$. Several options are available for the storage of $\mathrm{CO}_{2}$, including injection of $\mathrm{CO}_{2}$ into the ocean so that it gets carried into deep water, or more commonly by using geological formations as natural reservoirs, where wells are drilled and $\mathrm{CO}_{2}$ is be injected at depths of more than $1 \mathrm{~km}$.

\section{Implications of CCS for the water system}

Water and energy are strongly interrelated and the power sector withdraws more water than any other sector in the US [19]. Hence, introducing changes to existing power plants may significantly impact the sustainability of water resources. The deployment of CCS technologies in the power sector is expected to introduce potential challenges to water resources; therefore, in order to avoid unintended consequences, decision-makers must consider the interrelations between CCS deployments with the water system. The current article highlights three main challenges that can directly impact the sustainability of the water system due to introducing CCS technologies into power plants: (1) the amount of water required for CCS processes, (2) the change in groundwater quality due to possible leakage from $\mathrm{CO}_{2}$ sequestration, and (3) the feasibility to provide freshwater by treatment of brines produced during CCS operations in saline formations.

\section{Water use for CCS operations}

According to the US Geological Survey (USGS), in 2005, water withdrawals for thermoelectric power accounted for $41 \%$ of total freshwater use, $49 \%$ of total water use (fresh and saline), and 53\% of fresh surface water withdrawals for all industry sectors in the US. With approximately 760 million cubic meters of water being used each day in 2005 to produce electricity, thermoelectric power plants have been the largest water users in the country since 1965 . The primary use of water in thermoelectric power generation is for cooling purposes, which accounts for $80-99 \%$ of the raw water usage for different fossil-fuel plants [20].

The main sources of water supply in the US come from surface water in rivers and streams, as well as from groundwater aquifers. Figure 3 shows the distribution of surface and groundwater resources over the US, based on streamflow and groundwater recharges at the spatial scale of eight-digit hydrologic unit code (HUC8). As evident in this figure, many US regions are already under significant water shortages, especially those in the south and southwestern states that are witnessing significant increases in population and related urbanization demands. The impact on the current availability of water resources can be further exacerbated by changes introduced to the thermo-electric power generation sector, including retrofitting of power plants and CCS deployments. The introduction of CCS technologies requires additional amounts of water for chemical and physical processes to capture and separate large volumes of $\mathrm{CO}_{2}$. Figure 4 illustrates the change in water use in coal power plants with and without CCS unit installation. As seen in this figure, the water use (consumption or withdrawals) is almost doubled when a power plant becomes equipped with a CCS technology [21]. Also, it appears that a CCS-equipped power plant with a hybrid dry-wet cooling system is comparable to that of the base case plant that uses a wet tower system but without carbon capture. Furthermore, the addition of a CCS unit imposes parasitic power demand on the existing power plant and thus makes it less efficient. Such a load increases the heat rate at the power plant, and therefore, more water will be needed for the cooling process. Such parasitic loads associated with carbon capture can be reduced by using improved solvents, e.g., methyldiethanolamine/piperazine (MDEA/PZ) [22], and more efficient capture process configurations, e.g., absorber intercooling or stripper interheating [23].

\section{Impact on groundwater}

The second concern with CCS implementation is the potential hazard to groundwater due to $\mathrm{CO}_{2}$ leakage, which can occur as a result of well leakage, fault leakage, and cap rock leakage [24, 25]. The leakage of $\mathrm{CO}_{2}$ from deep geological storage sites could adversely impact water quality in overlying potable aquifers due to the potential mobilization of hazardous inorganic elements. When $\mathrm{CO}_{2}$ is dissolved in a freshwater aquifer, the total concentration of dissolved carbonate increases, which leads to significant increases in water acidity [26]. The resulting increase in concentration of hazardous elements could deteriorate groundwater quality to the extent that exceeds the maximum contaminant levels regulated by US Environmental Protection Agency (EPA). For instance, Pawar et al. [27] showed potential changes in groundwater chemical composition under different hypothetical $\mathrm{CO}_{2}$ leakage scenarios. They adapted multiple risk proxies for assessing impacts to groundwater including $\mathrm{pH}$, TDS, concentrations of heavy metals $(\mathrm{Pb}, \mathrm{As}, \mathrm{Cd}, \mathrm{Ba})$, and concentrations of organics (Naphthalene, Benzene, Phenol). The threshold values for these risk proxies can be defined using MCL or the secondary drinking water standard regulated by EPA $[28,29]$.

\section{Treatment of brines}

The third issue discussed in the context of CCS and water resources relates to opportunities presented by possible treatment of brines produced during CCS operations. The geologic sequestration of $\mathrm{CO}_{2}$ in pressure-constrained formations may generate large volumes of extracted brine, 

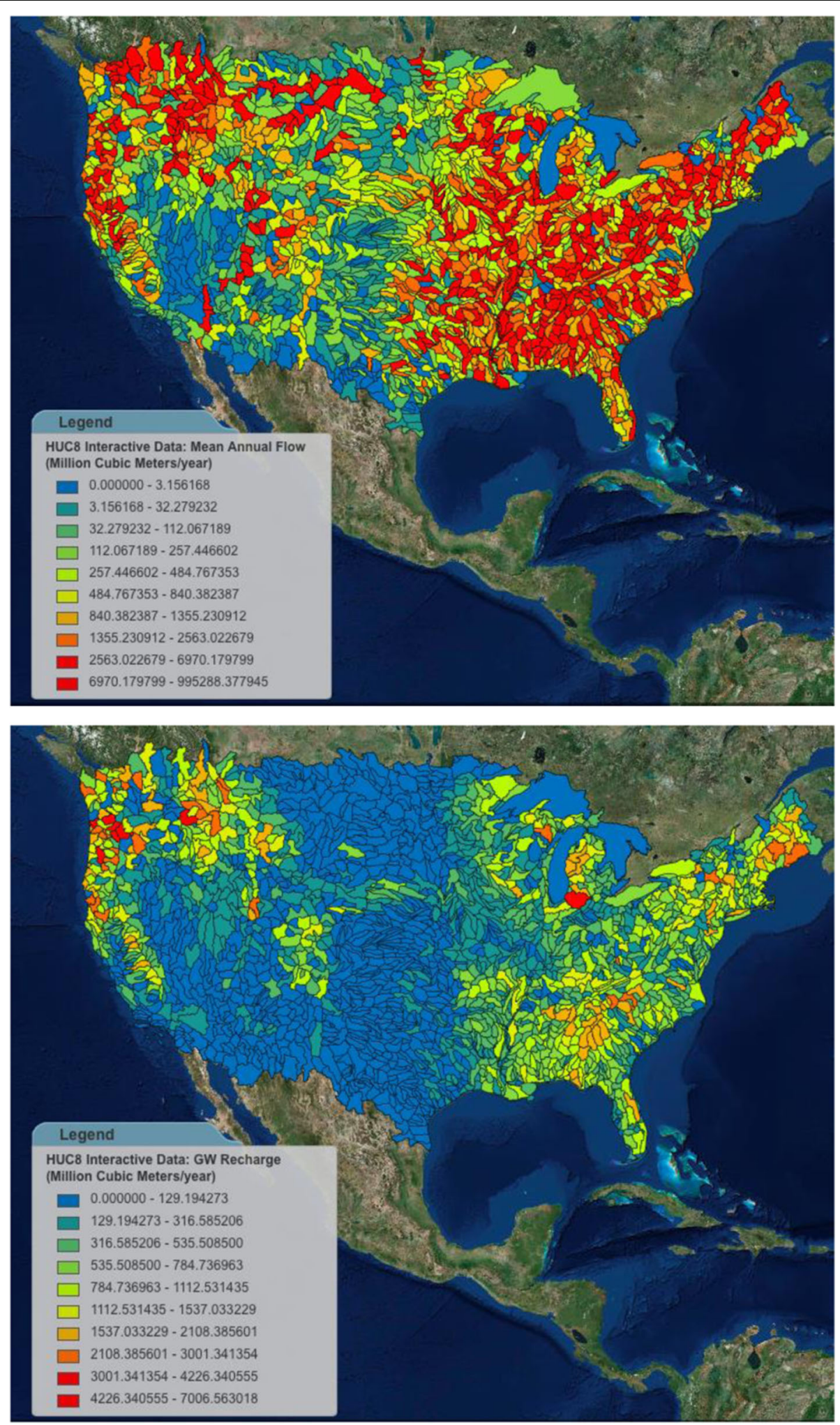

Fig. 3 Distribution of mean-annual surface water (top panel) and groundwater resources (lower panel) over the US. Graphs are generated using the Energy-Water nexus tool (http://nexus.hydroviz.org) 

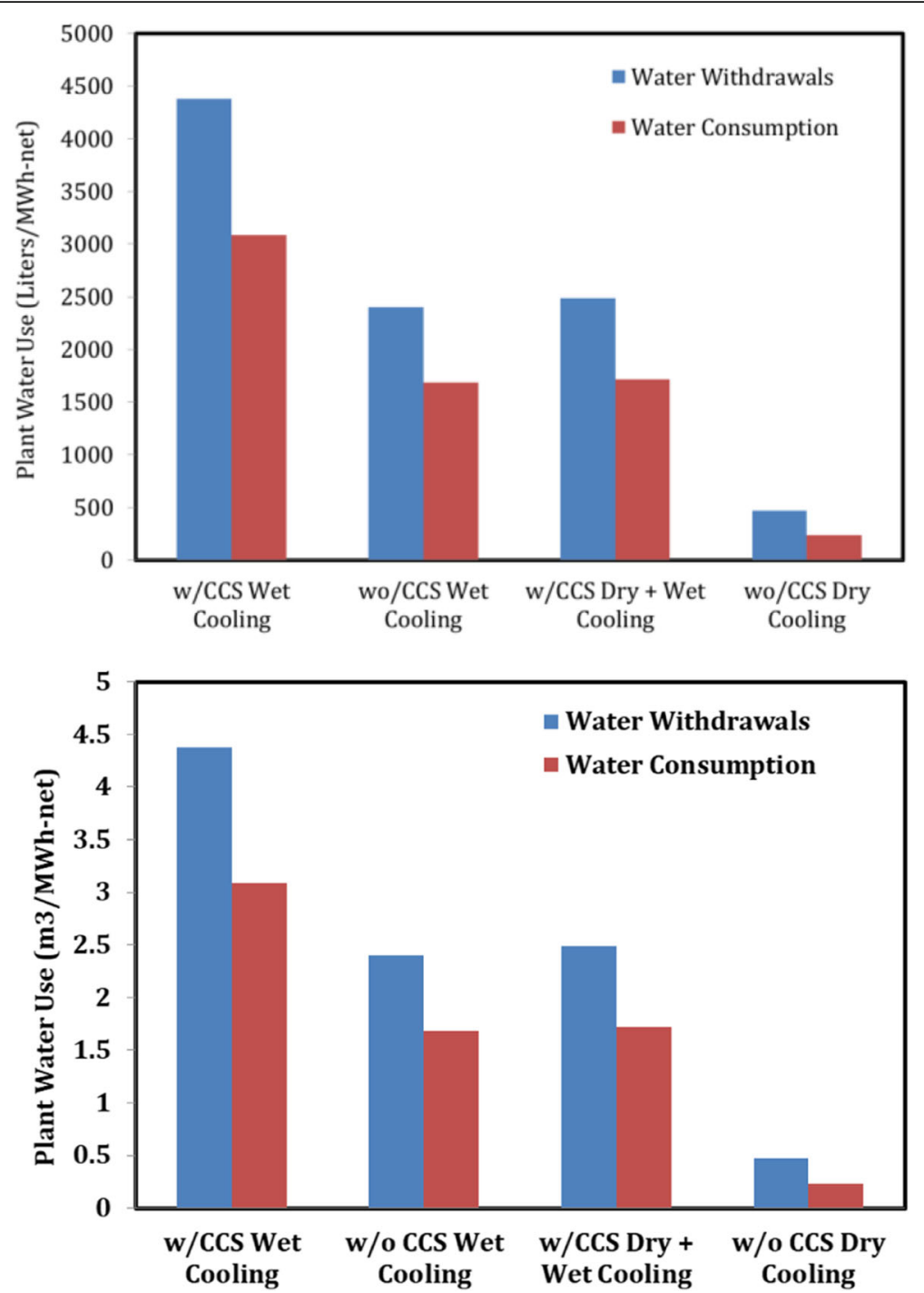

Fig. 4 Effects of primary cooling technology on plant water use at coal power plants with and without carbon capture and sequestration (CCS) (adapted from [21])

or saline water formations with total dissolved salts up to $85,000 \mathrm{ppm}$. With a potential intensification in the aquifer pressure due to $\mathrm{CO}_{2}$ storage, withdrawal of brine from the aquifer can help control aquifer pressures to within the desirable limits [30-32]. Apart from the primary advantage of brine withdrawal in pressure management, it could also provide a low-cost freshwater resource that counterbalances the water requirements of CCS operations. Freshwater can be produced by desalinating the produced brines using a suitable desalination technology, e.g., reverse osmosis [33]. According to Aines et al. [34], the reverse osmosis treatment of brine extracted from welldesigned capture systems in a typical $1 \mathrm{GW}$ coal plant would produce freshwater at a rate in the range of 0.7 to $1.4 \mathrm{~m}^{3}$ per metric ton of sequestrated $\mathrm{CO}_{2}$. This amount of water corresponds to the needs of half of the total freshwater consumption in a typical $1 \mathrm{GW}$ Integrated Gasification Combined Cycle (IGCC) power plant. The associated cost with the brine extraction and treatment is a key factor when assessing the produced freshwater as a CCS opportunity. Bourcier et al. [35] performed a cost analysis to compare the treatment of typical brines with conventional seawater desalination and found that predicted desalination costs for brines having salinities equal to seawater are about half the cost of conventional seawater desalination. This reduction in cost is attributed to the opportunity to retrieve energy from excess pressure at the sequestration site and use it to drive the desalination process. From this perspective, desalinated extracted brine can be considered as a potential source of freshwater to alleviate CCS-induced stresses on water systems. 


\section{Data and modeling resources}

Addressing potential impacts on the water system due to CCS installation requires a variety of datasets with different types and spatial reference systems (e.g., river basins, counties, electric grid). Water, energy, and carbon emission datasets are typically available through published literature, government and non-governmental reports, and submissions to government agencies for permitting processes [36]. Examples of currently available databases in the US include the following: (1) USGS databases and reports that provide historical time series of water withdrawal for power generation and other user sectors, such as irrigation, industrial, and public supply at the county scale; (2) the State Energy Data System (SEDS), managed by the US Energy Information Administrations (EIA) with comprehensive energy statistics; (3) the Emissions and Generation Resource Integrated Database (eGRID) that provides information on power plants by fuel type, utility versus non-utility designation, geographic location, installed capacity, and cooling type; and (4) EPA's Facility Level Information on GreenHouse gases Tool (FLIGHT), which can be used as an interactive online tool to download data on power plant carbon emissions.

Numerical simulations can be used to enhance the scientific understanding of carbon capture water requirements and geologic carbon sequestration impacts on groundwater. One example is the Carbon Capture Simulation Initiative (CCSI) toolset that integrates a suite of scientifically validated models for carbon capture and provides decision-making capabilities with uncertainty assessment [37]. Additionally, the Pacific Northwest National Laboratory (PNNL) has developed a numerical model of Subsurface Transport Over Multiple Phases (STOMP-CO2) to provide a practical tool of subsurface injection and long-term storage of carbon dioxide in deep subsurface reservoirs [38, 39]. STOMP is approved by the US Department of Energy to support environmental management decisions. Potential impacts to groundwater quality due to $\mathrm{CO}_{2}$ leakage could also be examined using numerical simulation. For example, the National Risk Assessment Partnership (NRAP) platform has been recently used by Pawar et al. [40] to quantify risks associated with $\mathrm{CO}_{2}$ and brine leakage using various leakage scenarios. Using NRAP-like simulations, the volume of groundwater within the shallow aquifers that exceeds certain water quality thresholds can be estimated according to pre-specified maximum contaminant level thresholds necessary to comply with designated contaminant levels.

\section{Illustrative CCS analysis from different US regions} This section presents two examples to illustrate the possible consequences of introducing a CCS unit at a power plant. The examples represent two states of the US, Louisiana and Arizona, with different climatic and water availability conditions. Louisiana represents a good example of US states with abundant surface water supply, while Arizona is located in the western US and is characterized by an arid and semi-arid climate with significant drought episodes [41-43]. Such variations in water variability will provide an insightful assessment of water requirements associated with CCS installation under different hydrologic conditions representing wet and dry climates.

\section{Example (1): potential for introducing CCS into existing plants}

According to the US Energy Information Administration (EIA), Louisiana accounts for about $4 \%$ of the total carbon dioxide emissions in the US. It is also one of the top ten states with the highest levels of energy-related $\mathrm{CO}_{2}$ emissions in 2013. Electricity is available in Louisiana through electric utilities (about 58\%) and independent power producers (about 42\%) that operate electric generating units [44]. The fuel sources for these generating units include fossil fuels (coal, natural gas, and petroleum), uranium, and renewable fuels (water, geothermal, wind, and other renewable energy sources). Figure 5 shows the $\mathrm{CO}_{2}$ emissions in Louisiana from the power generation sector based on three types of fuel: coal, natural gas, and petroleum. It is obvious that power plants fueled by coal contribute the most in terms of carbon emissions, followed by natural gas and petroleum fuel-fired plants. Carbon emission from coal combustion is approximately twice that from burning natural gas despite natural gas being the primary energy source for electricity generation in Louisiana (Fig. 6a).

In the Clean Power Plan (CPP) established by the Environmental Protection Agency (EPA), Louisiana's $2030 \mathrm{CO}_{2}$ emission goal is set to 1121 pounds per megawatt-hour. CCS is one of the viable strategies suggested by EPA in the CCP plan to achieve the interim (2022 to 2029) and final 2030 emission goals. To illustrate the possible consequences of adapting a CCS strategy, three pilot plants have been selected in Louisiana to discuss opportunities and feasibility of CCS installation for climate-change mitigation purposes. The three pilot power plants are as follows: the Big Cajun II (BCII), a coal-fired power station in Pointe Coupee Parish; the Brame Energy Center (BEC), fueled by petroleum products in Rapides Parish; and the Nine Mile Point (NMP), a natural gas-fired plant in Jefferson Parish (Fig. 6d). These plants represent three geographically diverse areas of the state, with differing water supply, water use, and $\mathrm{CO}_{2}$ storage capacity, and different fuel types with significant contribution in carbon emission. Figure $6 \mathrm{~b}$ shows the 2010 rates of water 


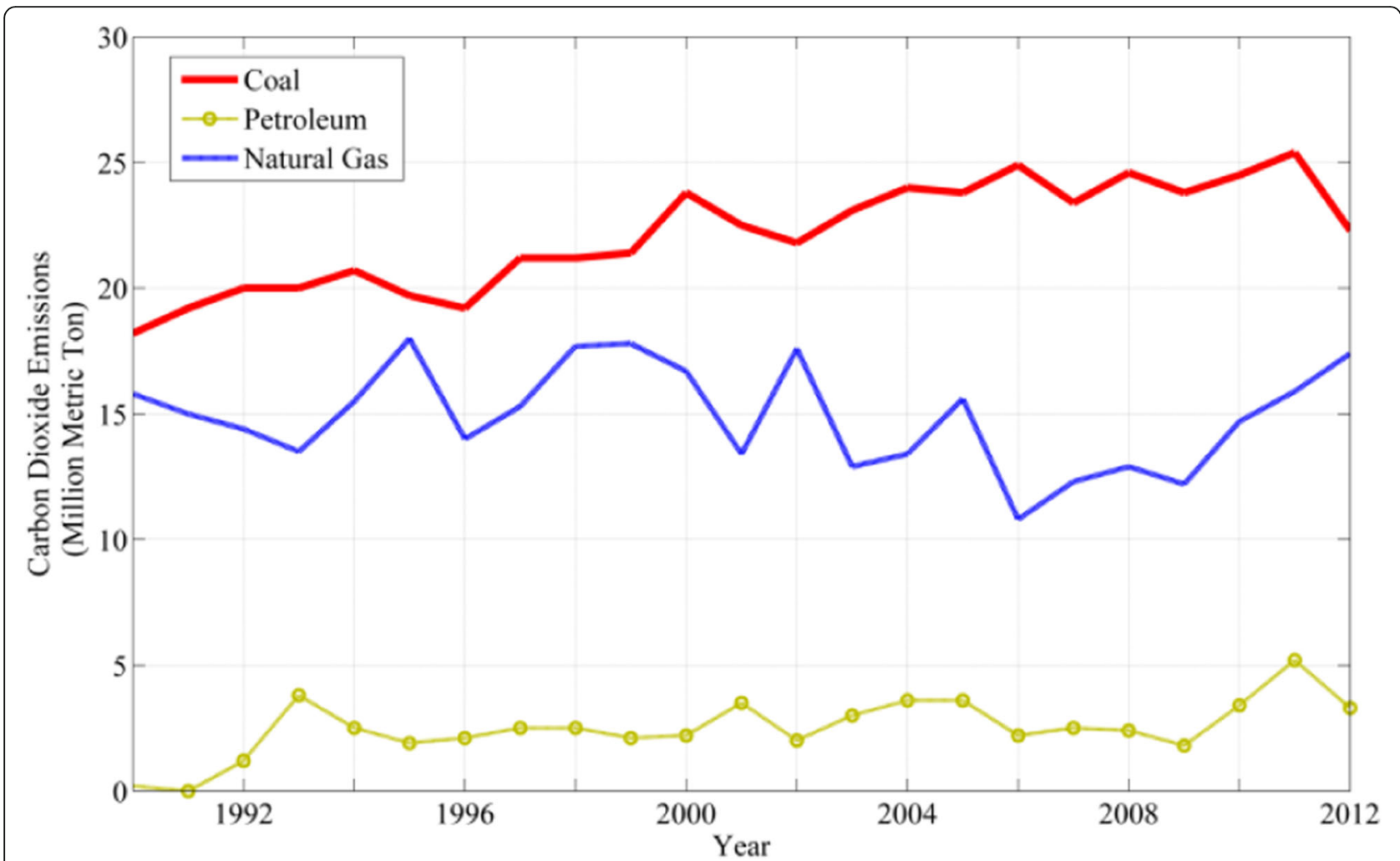

Fig. $5 \mathrm{CO}_{2}$ emission by fuel type in Louisiana during the period (1990-2012) [data source: EIA]

withdrawals by thermoelectric plants estimated by the USGS. The most water-consuming plants are the BEC plant, with about 2 million cubic meters, followed by the NMP plant, which withdraws 1.7 million cubic meters. The estimated carbon emission in thermoelectric plants is illustrated in Fig. 6c with the highest $\mathrm{CO}_{2}$ emission from the BCII plant (about 10.6 million metric ton), followed by the BEC and NMP plants. These plants have the highest requirements of water, as well as the largest amount of carbon emissions, which reflects the importance of evaluating CCS impacts on the water system.

Locations of saline aquifers in the US are provided in the National Carbon Sequestration Database (NATCARB). Aquifers with storage potential are listed by NATCARB, which were developed after initial site screening as possible candidates for use in geologic $\mathrm{CO}_{2}$ injection. Storage capacity is estimated based on the pore volume that can be occupied by injected $\mathrm{CO}_{2}$. Figure $6 \mathrm{~d}$ shows that the majority of Louisiana parishes, except for the northwestern part of the state, are at a suitable distance from the closest saline aquifer for $\mathrm{CO}_{2}$ sequestration. Moreover, the capacity of $\mathrm{CO}_{2}$ increases towards the Gulf of Mexico coastal zone. All these factors indicate the potential for CCS deployments and provide strong evidence to conduct future in-depth assessment for building CCS systems in states with high levels of energy-related $\mathrm{CO}_{2}$ emissions.

Further assessment of CCS potential sites should also include the extent of dependency on groundwater as a primary source of water supply to quantify risks due to possible CCS-related impacts on groundwater quality. In the presented example, the percentage of groundwater use to the total water withdrawal is calculated in each parish for three different sectors that primarily rely on groundwater: public supply, industrial, and aquaculture demands (Fig. 7). This figure illustrates that Pointe Coupee and Rapides Parishes are completely dependent on groundwater pumping for meeting demands from public supply and industrial sectors, while about $60 \%$ of water use for aquaculture is from groundwater. In Jefferson Parish, about $40 \%$ of the industrial water demand is pumped from groundwater wells. Therefore, potential changes in groundwater quality due to leakage of $\mathrm{CO}_{2}$ in geologic formations can significantly alter the water sustainability in these parishes.

\section{Example (2): added stresses on freshwater resources}

As discussed above, the deployment of CCS technologies at existing power plants has consequences for the water system and may add further stresses. The degree of 


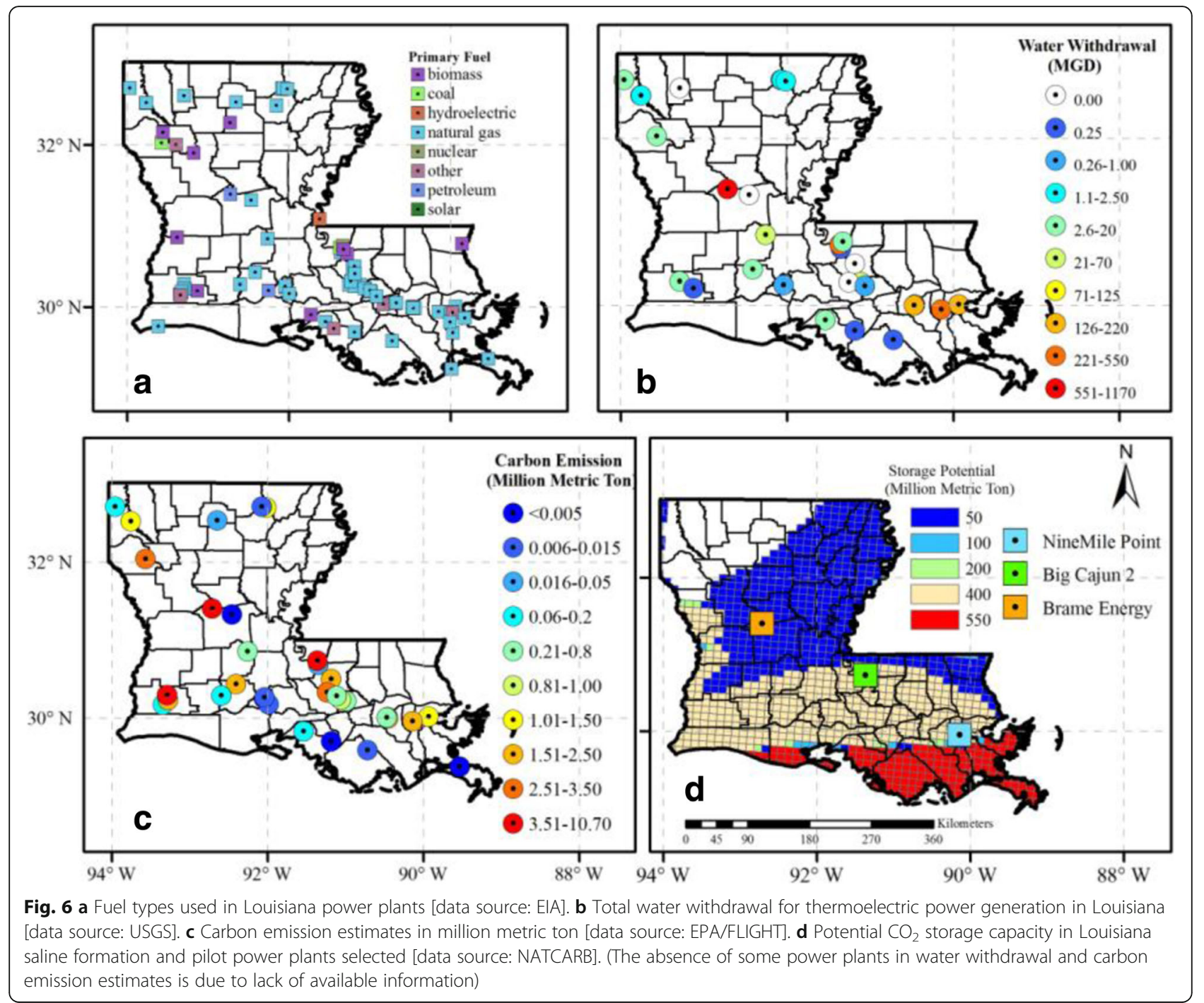

stress on the water system can be measured using different metrics that vary according to their spatial-scale applicability. Examples of these metrics include the water stress indicator for global-scale assessment [45], the criticality ratio for country-scale assessment [46], and the Water Supply Stress Index (WaSSI) for a hydrologic basin scale [47]. For illustrative purposes, the current study uses the WaSSI index to examine current stresses on the water resources and the potential CCS-induced stresses. The WaSSI index is expressed as a ratio of

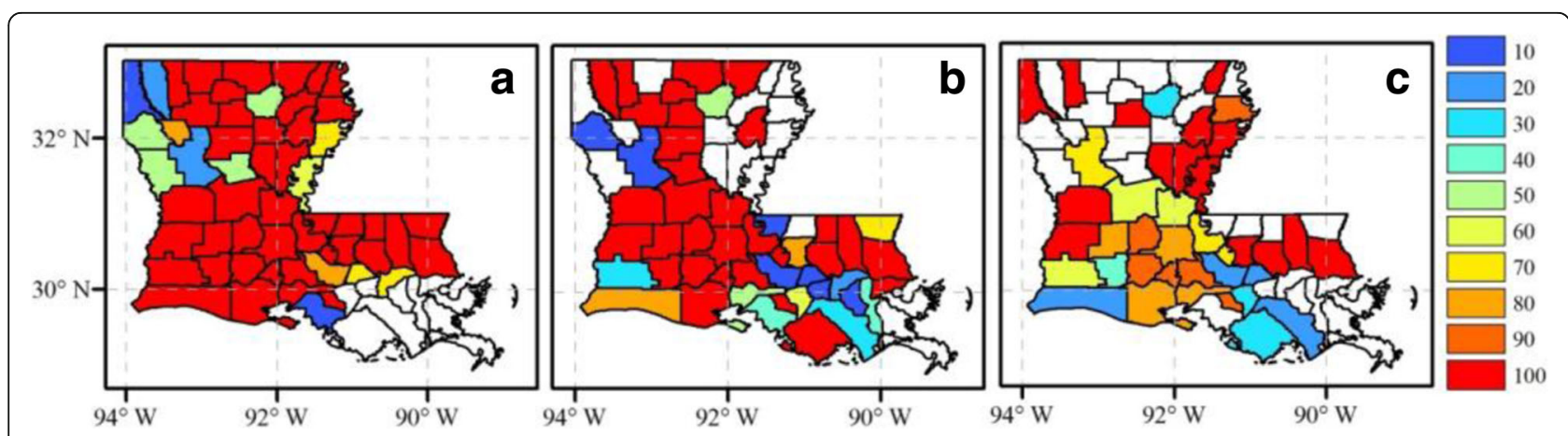

Fig. 7 Percentage of groundwater withdrawal by the (a) public, (b) industrial, and (c) aquaculture sectors [data source: USGS] 
average water demands (WD) to water supplies (WS) in the hydrologic basin under consideration:

$$
\mathrm{WaSSI}=\frac{\mathrm{WD}}{\mathrm{WS}}
$$

The greater the WaSSI value, the more stressed the water system is in the basin. The WD term accounts for consumptive water uses by sectors such as agriculture, municipalities, industry, and thermoelectric power generation. The WS term accounts for water from both surface (streamflow) and groundwater (recharge of aquifers) sources. The WaSSI formula was applied over each hydrologic unit in the US basins and is plotted in Fig. 8 for the southwestern US region. Full details on how the WS and WD terms were compiled for each basin are available in Eldardiry et al. [48]. The WaSSI results indicate that many US basins, such as those in the southwestern states, are subject to alarming rates of water stresses (e.g., WaSSI > 0.5).

The impact on the water system due to thermal power generation may vary according to the configurations of the power plant under consideration (e.g., fuel type, cooling type, and plant technology). To further illustrate this impact, a scenario-based analysis is performed for the Springville power plant (Fig. 9) located in the Upper Little Colorado watershed in the US state of Arizona (Table 1). Scenario A represents the existing power plant conditions with tower recirculating cooling technology, while scenarios from B to F reflect hypothetical scenarios that represent different possible retrofitting configurations. Retrofitting refers to the modification or addition of new technology to an existing power plant in order to achieve certain objectives such as improving power plant efficiency, increasing output, or reducing greenhouse gas emissions. Retrofitting options could include employing different cooling types and/or power plant technologies and installation of a CCS unit at the power plant facility to mitigate $\mathrm{CO}_{2}$ emissions. Two of the hypothetical retrofitting scenarios (D and $\mathrm{E}$ ) assume the introduction of a CCS unit to the power plant. This scenario-based analysis examines how introducing a CCS technology to the power plant, under different cooling types and power plant technology configurations, could change the stress on the water resources with respect to the reference scenario A.

The Springville power plant in Arizona is a coal-fired plant with a tower-recirculating cooling technique. The estimated amount of energy generated by this power plant is $8,871,873 \mathrm{MWh}$. According to these configurations, and based on an average water withdrawal of $687 \mathrm{gal} / \mathrm{MWh}$ [49], the amount of water needed for cooling purposes at this power plant is estimated to be 23.07 million cubic meters $\left(\mathrm{Mm}^{3}\right)$. Using the same WaSSI stress concept introduced earlier (Eq. 1), the basin where the power plant is located has a stress index of 0.68 (reference scenario A). If a CCS technology is introduced at this power plant (scenarios D and E), and

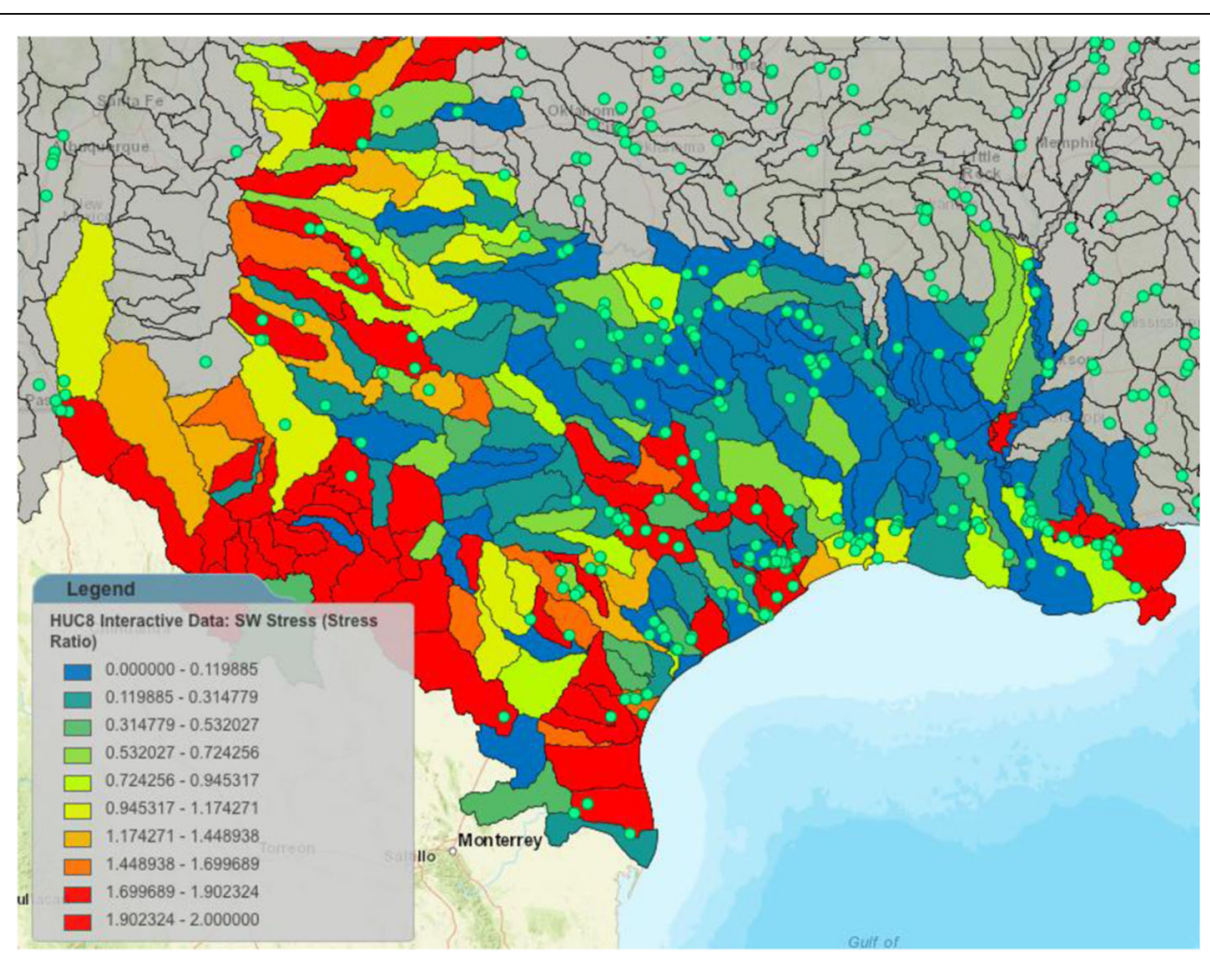

Fig. 8 Water Supply Stress Index (WaSSI) calculated at a hydrologic basin scale over selected states in the Southwestern US. The graph is generated using the Energy-Water nexus tool (http://nexus.hydroviz.org) 


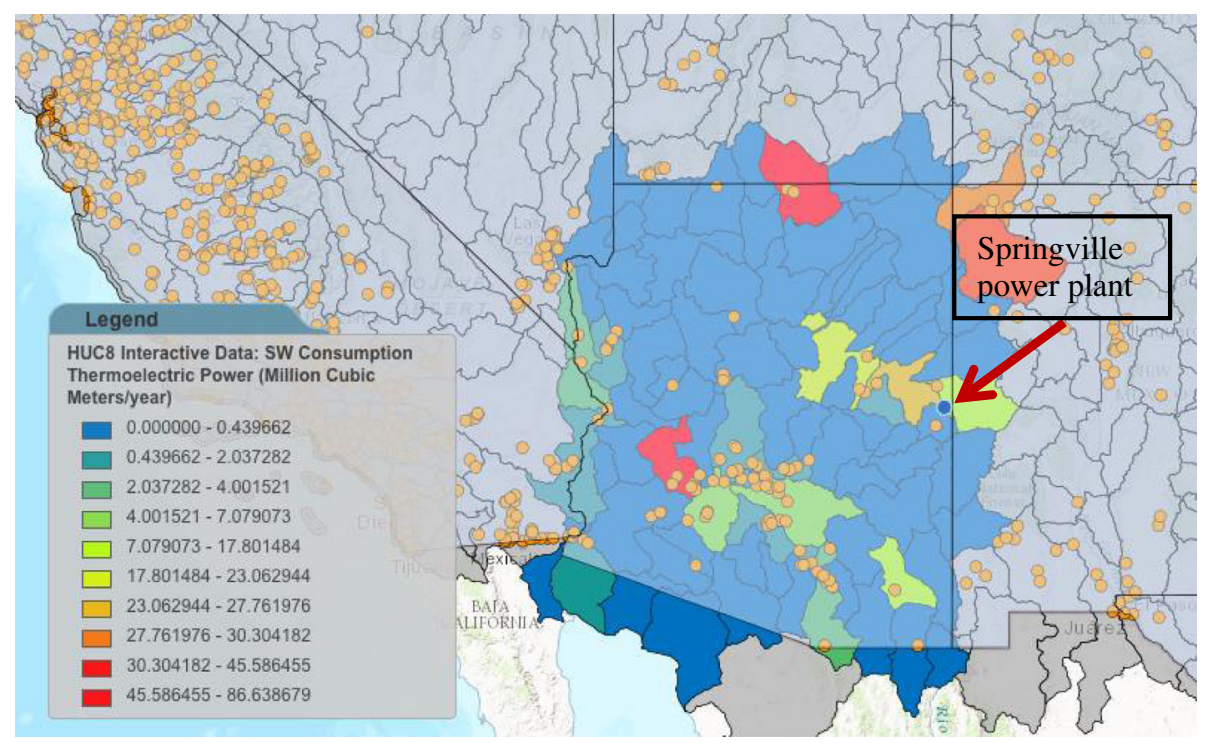

Fig. 9 The red arrow points to the location of the Springville power plant (blue circle) in Little Colorado watershed, Arizona. The background colors represent surface water (SW) withdrawals by the thermoelectric power sector. The graph is generated using the Energy-Water nexus tool (http://nexus.hydroviz.org)

depending on a set of pre-set combinations of power plant cooling types and plant technologies, the stress index in the basin increases significantly as indicated in Fig. 10. By analyzing the two CCS scenarios D and E, the installation of a CCS resulted in about 40 and $50 \%$ of added stresses compared to scenarios B and C respectively. These results indicate how adding CCS can place significant impacts on the water system, especially in basins with relatively low water resources. Further stresses on the water system can be expected when future CCS deployments are aligned with growths in populations and related water and energy demands. This illustrative example is implemented by using the EnergyWater nexus interactive web tool [50]. Through this tool (http://nexus.hydroviz.org), additional scenarios of cooling technology and CCS installation can be tested for other states.

Table 1 Scenarios of power plant configurations and CCS deployment used in assessing the impacts on the water system (see Fig. 10)

\begin{tabular}{lll}
\hline Scenario & Plant cooling system & Plant technology \\
\hline (A) & Tower recirculating & $\begin{array}{l}\text { Generic } \\
\text { Sub-critical pulverized coal } \\
\text { combustion }\end{array}$ \\
(C) & Tower recirculating & $\begin{array}{l}\text { Super-critical pulverized coal } \\
\text { combustion }\end{array}$ \\
(D) & Tower recirculating & Same as (B) but with CCS \\
(E) & Tower recirculating & Same as (C) but with CCS \\
(F) & Once-through & Generic \\
\hline
\end{tabular}

\section{Environmental and socio-economic impacts of CCS operations}

Despite their main function as a climate mitigation measure, the deployment of CCS technologies poses environmental, economic, and societal concerns. Gibbins et al. [16] pointed out two main barriers to CCS projects: the need for large and long-term funding sources in order to achieve significant reduction in carbon emissions and the need for regulatory frameworks for the transport and geological storage of $\mathrm{CO}_{2}$. Therefore, there is a need to comprehensively address the environmental, economic, and societal impacts to assess the viability of successful CCS interventions.

\section{Environmental impacts}

The key advantage of introducing CCS technologies into power plants is that it allows for the use of lowcost fossil fuels for electric generation while reducing the contribution to greenhouse emissions and potential global warming. However, CCS faces a number of environmental barriers that must be investigated before it can be deployed on a large scale. CCS environmental risks are grouped into local and global effects. Local effects are those impacts associated with leakage of $\mathrm{CO}_{2}$ within the CCS system via bore holes overlaying rocks or natural fractures and faults [12]. Such leakage can significantly impact groundwater chemistry and the quality of drinking water. Larger scale hazards include the effects on global climate due to possible low-level $\mathrm{CO}_{2}$ leaked back into the atmosphere. 


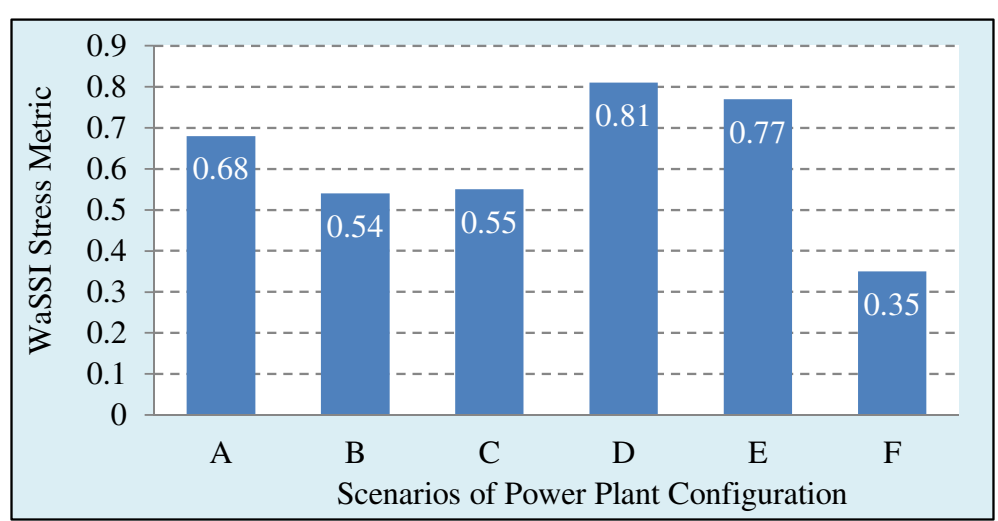

Fig. 10 Impact of CCS deployment under different power plant configurations for the Springville power plant, Arizona, Southwestern US

This could happen because of a structural geologic failure that would lead to an immediate release of a high concentration of $\mathrm{CO}_{2}$ back into the atmosphere. Hence, a systematic approach for evaluating the complete life cycle for different CCS options is highly recommended. Examples of recent studies that employed Life Cycle Assessment (LCA) as a well-established method to assess environmental consequences of CCS include Rao et al. [51], Viebahn et al. [52], and Pehnt et al. [53].

\section{Economic impacts}

Stakeholders and policymakers are interested in economically competitive options to reduce greenhouse gas emissions. Therefore, besides technical understanding of CCS, exploring the costs incurred in CCS operations is necessary to fully understand the economics of CCS technologies. Several studies evaluated the economic impacts of CCS on the energy systems (see for example Biggs et al. [54]; David and Herzog [55]; and McFarland et al. [56]). For instance, David and Herzog [55] analyzed the costs associated with $\mathrm{CO}_{2}$ capture technology and concluded that 1.5-2 cents $/ \mathrm{kWh}$ would be added to the cost of electricity for an integrated coal gasification-combined cycle or natural gas-combined cycle power plants. This cost increases for a pulverized coal plant to over 3 cents/ $\mathrm{kWh}$. These costs will be added to the transportation and storage of $\mathrm{CO}_{2}$ that are estimated to be at an average cost of $4.89 \mathrm{USD} /$ metric ton $\mathrm{CO}_{2}$ for US $[57,58]$. A promising approach to reduce the CCS associated costs is to consider the development of CCS clusters where $\mathrm{CO}_{2}$ can be collected from clusters of power stations and other industries with high carbon emissions and then transported to the storage site $[10,59]$. This approach can efficiently reduce $\mathrm{CO}_{2}$ compression and related infrastructure by sharing the same transport pipelines. Future studies should also consider the cost effectiveness of bio-energy in combination with CCS, known by the acronym BECCS or Bio-CCS, as an attractive technology to meet lower carbon concentration targets compared with other conventional mitigation options, [60-63].

An important CCS economic factor is determining which power plants are suitable for retrofitting versus building new plants with CCS units. Earlier assessment by the Intergovernmental Panel on Climate Change (IPCC) in 2007 concluded that retrofitting existing plants with $\mathrm{CO}_{2}$ capture will lead to higher costs and significantly reduced overall efficiencies compared to building new power plants [64]. Besides the cost associated with CCS retrofit, additional disadvantages are listed in IPCC [64] including potential site-specific constraints (e.g., lack of availability of land for the capture equipment), as well as a tendency to have low efficiencies and, consequently, a proportionally greater impact on the net output than in high-efficiency plants. Finkenrath et al. [65] defined the potential to retrofit CCS units at power plants based on the following criteria: theoretical, technical, cost-effective, and realistic potentials. Theoretically, it is viable to retrofit CCS to all operating power plants; however, this potential reduces significantly when considering technical, economical, and realistic constraints. Future efforts need to be directed towards the integration of energy and water systems in CCS economic assessment and identifying cost-efficient CCS technologies, in terms of both the energy and the water markets. Economic models can be used to assess the capital and operating costs over the life of an investment necessary to meet $\mathrm{CO}_{2}$ emission reduction goals. Metrics to evaluate CCS efficiency can include the cost of $\mathrm{CO}_{2}$ avoided, cost of $\mathrm{CO}_{2}$ captured, cost of $\mathrm{CO}_{2}$ abated, and the increased cost of electricity. A comprehensive water-energy economic analysis 
can therefore help address the following critical issues in CCS operations:

(1) The financial gap between "with CCS" versus "without CCS"

(2) Retrofitting of CCS to existing power plants versus building new plants equipped with CCS units based on plant age and/or size

(3) The cost of electricity generation with different CCS technologies deployment, e.g., post-combustion versus pre-combustion capture techniques

(4) Projection of net impacts on water costs with the implementation of CCS due to potential changes in groundwater and surface water resources

(5) Costs associated with desalination of brine to produce freshwater

\section{Societal impacts}

Societal acceptance is a crucial aspect of new energy technology applications, and as such should be considered in the case of CCS projects. Public acceptance is likely to be influenced by risk-benefit perceptions and informational provision [66]. Public perception of risks associated with CCS may arise due to concerns about the sequestration technology and potential leakage of $\mathrm{CO}_{2}$ [67]. It is therefore imperative to develop a direct communication with stakeholders, policymakers, and the general public to increase awareness of CCS operations and to discuss the associated risks and benefits. Communication strategies may include online surveys and face-to-face interviews that address public attitudes towards global climate change, climate change-mitigation technologies with an emphasis on CCS, and impacts of electricity generation on water systems. Table 2 lists examples for the primary factors and the accompanied determinants that can be considered in building a survey to reflect the public acceptance of CCS. The survey and interview responses can be incorporated with demographic variables and statistical models to generate trending data that gauge public perceptions of CCS technologies, environmental concerns, and contributions in mitigation of global climate change.

\section{Conclusions}

CCS has been proposed as a viable climate-change mitigation measure to reduce greenhouse gas emissions with the continued use of fossil fuels in electricity generation.
However, CCS-equipped power plants have shown significant increases in water consumption, in the range of 45 to $90 \%$. This paper reviews the available literature on CCS technologies and focuses mainly on the potential impacts on water system sustainability. The literature review presented in this paper highlights water-related challenges with CCS including the following: (1) quantification of water requirements for physical and chemical processes in CCS and the water needed for cooling the power plant due to parasitic load imposed by the carbon capture process, (2) prediction of $\mathrm{CO}_{2}$ migration in a wide range of geological formations to study the potential leakage of $\mathrm{CO}_{2}$ and the related impacts on groundwater quality, and (3) opportunities to use the extracted brine to make the existing water systems less vulnerable to CCS installation. Analysis of these water aspects with CCS involves the use of various datasets that are available from published academic literature, state and federal agencies, and non-governmental organizations. Integrating these datasets with available simulation tools can provide a basis for improved CCS analysis and help decisionmakers in testing alternative scenarios.

This study presented an illustrative analysis for different regions of the US to show potential impacts of CCS on the water system. The analysis underlines the increase in water consumption with CCS installation compared to generic configuration of power plants with no CCS. The analysis also illustrated the risks associated with $\mathrm{CO}_{2}$ leakage, especially in areas that primarily depend on groundwater as a freshwater resource for certain demand sectors (e.g., aquaculture uses). Future applications would also include the possibility of using extracted brine as a freshwater source that can alleviate stresses in areas with water supply shortages. However, the economic feasibility of the extracted brines should be first assessed and compared against other resources, such as treatment of wastewater. Furthermore, the added stresses to the existing water systems suggest the potential use of alternative water resources in the cooling of power plants equipped with CCS. Examples for such alternative resources include municipal wastewater and brackish groundwater $[36,68]$.

CCS impacts need to be communicated with policy makers, stakeholders, the environmental community, and general public to educate them on the possibilities and limitations of CCS approach compared to other climate mitigation options. Hence, unlike previous studies

Table 2 Factors and determinants affecting public acceptance of CCS [66, 67, 71, 72]

\begin{tabular}{lllll}
\hline Public cognition (PC) & Perceived risks (PR) & Perceived benefits (PB) & Environmentalism (EM) & Public trust (PT) \\
\hline Knowledge of CCS & Physical health & Electricity price & Emission reductions & Stakeholder credibility \\
Related mitigation technologies & Carbon leakage & Job opportunities & Water availability & Competence \\
Temporality & Earthquakes & Financial compensation & Drinking water quality & Communication \\
\hline
\end{tabular}


that assess the sustainability of water systems based only on water availability only, future studies should adopt a combined sustainability score to address the overall performance of the system under environmental, economic, and societal impacts (see for example the framework provided by Kjeldsen and Rosbjerg [69]. The CCS and impacts on freshwater resources highlight the growing interest in studying the water and energy in a holistically nexus approach [70]. Despite the complexity of building energy-water nexus models, using these models in future research will provide a promising way to elucidate CCS among other key drivers governing water demand for electricity, such as population growth, cooling technology, fuel portfolios, and electricity trade.

\begin{abstract}
Abbreviations
BCII: Big Cajun II Power Plant; BEC: Brame Energy Center Power Plant; CCS: Carbon capture and sequestration; CCSI: Carbon Capture Simulation Initiative; $\mathrm{CO}_{2}$ : Carbon dioxide; CPP: Clean Power Plant; eGRID: Emissions and Generation Resource Integrated Database; EIA: Energy Information Administration; EPA: Environmental Protection Agency; FLIGHT: Facility Level Information on GreenHouse gases Tool; GHG: Greenhouse gases; HUC8: Eight-digit hydrologic unit code; IGCC: Integrated Gasification Combined Cycle; IPCC: Intergovernmental Panel on Climate Change; LCA: Life Cycle Assessment; NATCARB: National Carbon Sequestration Database; NMP: Nine Mile Point power plant; NRAP: National Risk Assessment Partnership; PNNL: Pacific Northwest National Laboratory; SEDS: State Energy Data System; STOMP: Subsurface Transport Over Multiple Phases; USGS: US Geological Survey; WaSSI: Water Supply Stress Index; WD: Water demand; WS: Water supply
\end{abstract}

\section{Acknowledgements}

This study is based upon work supported by the National Science Foundation under Grant No. (Award \# 1122898) with a Food, Energy, and Water supplement. The authors acknowledge energy and water datasets contributed by Dr. Vincent C. Tidwell from Sandia National Laboratories. The authors also thank Daniel J. Webre for his assistance with the language editing.

\section{Authors' contributions}

$\mathrm{Hd}$ conceived and designed the study, carried out data analysis and drafted the manuscript. EH participated in the design of the study, contributed to the interpretation of data and critically reviewed the draft of the manuscript providing substantial contributions to improve the analysis. Both authors read and approved the final manuscript.

\section{Competing interests}

The authors declare that they have no competing interests.

\section{Publisher's Note}

Springer Nature remains neutral with regard to jurisdictional claims in published maps and institutional affiliations.

Received: 24 July 2017 Accepted: 2 January 2018

Published online: 01 February 2018

\section{References}

1. Arnell NW (1999) Climate change and global water resources. Glob Environ Chang 9:S31-S49

2. Vörösmarty CJ, Green P, Salisbury J et al (2000) Global water resources: vulnerability from climate change and population growth. Science 289(5477):284-288

3. Olivier JG, Van Aardenne JA, Dentener FJ et al (2005) Recent trends in global greenhouse gas emissions: regional trends 1970-2000 and spatial distribution of key sources in 2000. Environ Sci 2(2-3):81-99

4. IPCC (2015) Climate change 2014: mitigation of climate change, vol 3. Cambridge University Press, Cambridge and New York
5. Mach K, Mastrandrea M (2014) Climate change 2014: impacts, adaptation, and vulnerability, vol 1. Cambridge University Press, New York

6. Chu S (2009) Carbon capture and sequestration. Science 325(5948): 1599-1599

7. Smith HJ, Fahrenkamp-Uppenbrink J, Coontz R et al (2009) Carbon capture and sequestration. Science 325:1641

8. Figueroa JD, Fout T, Plasynski S et al (2008) Advances in $\mathrm{CO}_{2}$ capture technology - the US Department of Energy's Carbon Sequestration program. Int I Greenhouse Gas Control 2(1):9-20

9. Herzog $\mathrm{H}$ (2001) What future for carbon capture and sequestration? Environ Sci Technol-Columbus 35(7):148A

10. Haszeldine RS (2009) Carbon capture and storage: how green can black be? Science 325(5948):1647-1652

11. Newmark RL, Friedmann SJ, Carroll SA (2010) Water challenges for geologic carbon capture and sequestration. Environ Manag 45(4):651-661

12. Metz B, Davidson O, de Coninck H et al (2005) Carbon dioxide capture and storage

13. Yang $\mathrm{H}, \mathrm{Xu} \mathrm{Z}$, Fan $\mathrm{M}$ et al (2008) Progress in carbon dioxide separation and capture: a review. J Environ Sci 20(1):14-27

14. Fout T, Murphy JT (2009) DOE/NETL's Carbon Capture R\&D Program for existing coal-fired power plants

15. Cuéllar-Franca RM, Azapagic A (2015) Carbon capture, storage and utilisation technologies: a critical analysis and comparison of their life cycle environmental impacts. J $\mathrm{CO}_{2}$ Util 9:82-102

16. Gibbins J, Chalmers H (2008) Carbon capture and storage. Energy Policy 36(12):4317-4322

17. Doughty C, Freifeld BM, Trautz RC (2008) Site characterization for CO2 geologic storage and vice versa: the Frio brine pilot, Texas, USA as a case study. Environ Geol 54(8):1635-1656

18. Gibson-Poole CM, Svendsen L, Underschultz I et al (2008) Site characterisation of a basin-scale $\mathrm{CO}_{2}$ geological storage system: Gippsland Basin, southeast Australia. Environ Geol 54(8):1583-1606

19. Maupin MA, Kenny JF, Hutson SS et al (2014) Estimated use of water in the United States in 2010 (no. 1405). US geological survey

20. Macknick J, Newmark R, Heath G et al (2011) Review of operational water consumption and withdrawal factors for electricity generating technologies (no. NREL/TP-6A20-50900). National Renewable Energy Laboratory (NREL), Golden

21. Zhai H, Rubin ES, Versteeg PL (2011) Water use at pulverized coal power plants with postcombustion carbon capture and storage. Environ Sci Technol 45(6):2479-2485

22. Closmann F, Nguyen T, Rochelle GT (2009) MDEA/piperazine as a solvent for $\mathrm{CO}_{2}$ capture. Energy Procedia 1(1):1351-1357

23. Rochelle GT (2009) Amine scrubbing for $\mathrm{CO}_{2}$ capture. Science 325(5948):1652-1654

24. Keating $\mathrm{EH}$, Hakala JA, Viswanathan $\mathrm{H}$ et al (2011) The challenge of predicting groundwater quality impacts in a $\mathrm{CO}_{2}$ leakage scenario: results from field, laboratory, and modeling studies at a natural analog site in New Mexico, USA. Energy Procedia 4:3239-3245

25. Wilkin RT, DiGiulio DC (2010) Geochemical impacts to groundwater from geologic carbon sequestration: controls on $\mathrm{pH}$ and inorganic carbon concentrations from reaction path and kinetic modeling. Environ Sci Technol 44(12):4821-4827

26. Apps JA, Zheng L, Zhang $Y$ et al (2010) Evaluation of potential changes in groundwater quality in response to $\mathrm{CO}_{2}$ leakage from deep geologic storage. Transp Porous Media 82(1):215-246

27. Pawar RJ, Bromhal GS, Chu S et al (2016) The National Risk Assessment Partnership's integrated assessment model for carbon storage: a tool to support decision making amidst uncertainty. Int J Greenhouse Gas Control 52:175-189

28. Acrylamide OC (2009) National Primary Drinking Water Regulations

29. Last GV, Murray CJ, Bott Y et al (2014) Threshold values for identification of contamination predicted by reduced-order models. Energy Procedia 63: 3589-3597

30. Cihan A, Birkholzer JT, Bianchi M (2015) Optimal well placement and brine extraction for pressure management during $\mathrm{CO}_{2}$ sequestration. Int J Greenhouse Gas Control 42:175-187

31. Breunig HM, Birkholzer JT, Borgia A et al (2013) Regional evaluation of brine management for geologic carbon sequestration. Int J Greenhouse Gas Control 14:39-48

32. Birkholzer JT, Cihan A, Zhou Q (2012) Impact-driven pressure management via targeted brine extraction - conceptual studies of $\mathrm{CO}_{2}$ storage in saline formations. Int J Greenhouse Gas Control 7:168-180 
33. Fritzmann C, Löwenberg J, Wintgens T et al (2007) State-of-the-art of reverse osmosis desalination. Desalination 216(1-3):1-76

34. Aines RD, Wolery TJ, Bourcier WL et al (2011) Fresh water generation from aquifer-pressured carbon storage: feasibility of treating saline formation waters. Energy Procedia 4:2269-2276

35. Bourcier WL, Wolery TJ, Wolfe T et al (2011) A preliminary cost and engineering estimate for desalinating produced formation water associated with carbon dioxide capture and storage. Int J Greenhouse Gas Control 5(5): 1319-1328

36. Tidwell VC, Moreland BD, Zemlick KM et al (2014) Mapping water availability, projected use and cost in the western United States. Environ Res Lett 9(6):064009

37. Miller DC, Syamlal M, Mebane DS et al (2014) Carbon capture simulation initiative: a case study in multiscale modeling and new challenges. Annu Rev Chem Biomol Eng 5:301-323

38. Saripalli KP, McGrail BP, White MD et al (2001) Modeling the sequestration of $\mathrm{CO} 2$ in deep geological formations. Laboratory directed research and development annual report-fiscal year 2000, p 233

39. White MD, Bacon DH, McGrail BP et al (2012) STOMP subsurface transport over multiple phases: STOMP-CO2 and STOMP-CO2e guide: version 1.0 (no. PNNL-21268). Pacific Northwest National Laboratory (PNNL), Richland

40. Pawar R, Bromhal G, Carroll S et al (2014) Quantification of key long-term risks at $\mathrm{CO} 2$ sequestration sites: latest results from US DOE's National Risk Assessment Partnership (NRAP) project. Energy Procedia 63:4816-4823

41. Anderson MT, Woosley LH (2005) Water availability for the western United States: key scientific challenges

42. Andreadis KM, Lettenmaier DP (2006) Trends in 20th century drought over the continental United States. Geophys Res Lett 33(10):L10403

43. Padowski JC, Jawitz JW (2012) Water availability and vulnerability of 225 large cities in the United States. Water Resour Res 48(12):W12529

44. Nussbaum P (2007) Louisiana electric generation-2007 update

45. Smakhtin V, Revenga C, Döll P (2004) A pilot global assessment of environmental water requirements and scarcity. Water Int 29(3):307-317

46. Alcamo J, Henrichs T, Rosch T (2000) World water in 2025. World water series report, $p 2$

47. Sun G, McNulty SG, Moore Myers JA et al (2008) Impacts of multiple stresses on water demand and supply across the southeastern United States. J Am Water Resour Assoc 44(6):1441-1457

48. Eldardiry H, Habib EH, Borrok DM (2016) Small-scale catchment analysis of water stress in wet regions of the US: an example from Louisiana. Environ Res Lett 11:124031

49. Macknick J, Sattler S, Averyt K et al (2012) The water implications of generating electricity: water use across the United States based on different electricity pathways through 2050. Environ Res Lett 7(4):045803

50. Habib E, Eldardiry H, Tidwell VC (2017) A New Interactive Web Platform to Support Education on Energy-Water Nexus. Eos Trans AGU (in press)

51. Rao AB, Rubin ES (2002) A technical, economic, and environmental assessment of amine-based CO2 capture technology for power plant greenhouse gas control. Environ Sci Technol 36(20):4467-4475

52. Viebahn $\mathrm{P}$, Nitsch J, Fischedick M et al (2007) Comparison of carbon capture and storage with renewable energy technologies regarding structural, economic, and ecological aspects in Germany. Int J Greenhouse Gas Control 1(1):121-133

53. Pehnt M, Henkel J (2009) Life cycle assessment of carbon dioxide capture and storage from lignite power plants. Int J Greenhouse Gas Control 3(1):49-66

54. Biggs S, Herzog H, Reilly J et al (2000) Economic modeling of $\mathrm{CO}_{2}$ capture and sequestration. In: Fifth international conference on greenhouse gas control technologies, Cairns, Australia, pp 13-16

55. David J, Herzog H (2000) The cost of carbon capture. In: Fifth international conference on greenhouse gas control technologies, Cairns, Australia, pp 13-16

56. McFarland J, Herzog H, Reilly J et al (2001) Economic modeling of carbon capture and sequestration technologies. Massachusetts Institute of Technology, Cambridge Mimeographed document

57. Leung DY, Caramanna G, Maroto-Valer MM (2014) An overview of current status of carbon dioxide capture and storage technologies. Renew Sust Energ Rev 39:426-443

58. Dahowski RT, Davidson CL, Dooley JJ (2011) Comparing large scale CCS deployment potential in the USA and China: a detailed analysis based on country-specific $\mathrm{CO}_{2}$ transport \& storage cost curves. Energy Procedia 4: 2732-2739
59. Byers EA, Hall JW, Amezaga JM et al (2016) Water and climate risks to power generation with carbon capture and storage. Environ Res Lett 11(2):024011

60. Venton D (2016) Core concept: can bioenergy with carbon capture and storage make an impact? Proc Natl Acad Sci 113(47):13260-13262

61. Gough C, Upham P (2011) Biomass energy with carbon capture and storage (BECCS or Bio-CCS). Greenhouse Gases Sci Technol 1(4):324-334

62. Azar $C$, Lindgren $K$, Obersteiner $M$ et al (2010) The feasibility of low $\mathrm{CO}_{2}$ concentration targets and the role of bio-energy with carbon capture and storage (BECCS). Clim Chang 100(1):195-202

63. Rhodes JS, Keith DW (2005) Engineering economic analysis of biomass IGCC with carbon capture and storage. Biomass Bioenergy 29(6):440-450

64. IPCC (2007) Intergovernmental panel on climate change. Climate change 2007: Synthesis report

65. Finkenrath M, Smith J, Volk D (2012) CCS retrofit: analysis of the globally installed coal-fired power plant fleet

66. Yang L, Zhang X, McAlinden KJ (2016) The effect of trust on people's acceptance of CCS (carbon capture and storage) technologies: evidence from a survey in the People's Republic of China. Energy 96:69-79

67. Selma L, Seigo O, Dohle S et al (2014) Public perception of carbon capture and storage (CCS): a review. Renew Sust Energ Rev 38:848-863

68. Stillwell AS, Webber ME (2014) Geographic, technologic, and economic analysis of using reclaimed water for thermoelectric power plant cooling. Environ Sci Technol 48(8):4588-4595

69. Kjeldsen TR, Rosbjerg D (2001) A framework for assessing the sustainability of a water resources system. IAHS PUBLICATION, Wallingford, pp 107-114

70. Averyt K, Fisher J, Huber-Lee A et al (2011) Freshwater use by US power plants: electricity's thirst for a precious resource

71. Curry TE, Ansolabehere S, Herzog H (2007) A survey of public attitudes towards climate change and climate change mitigation technologies in the United States: analyses of 2006 results. Publication no. LFEE, 1

72. Desbarats J, Upham P, Riesch H et al (2010) Review of the public participation practices for CCS and non-CCS projects in Europe. Report of the FP7 project "NearCO2, p 11

\section{Submit your manuscript to a SpringerOpen ${ }^{\circ}$ journal and benefit from:}

- Convenient online submission

- Rigorous peer review

- Open access: articles freely available online

- High visibility within the field

Retaining the copyright to your article

Submit your next manuscript at springeropen.com 